\title{
The role of cooperative learning with team assisted individualization to improve the students' self proficiency
}

\author{
Georgina Maria Tinungki \\ Mathematics Department, Mathematics and Natural Sciences Faculty, \\ Hasanuddin University Makassar
}

\begin{abstract}
The importance of learning mathematics can not be separated from its role in all aspects of life. This research aims to analyze the achievement of the students' self-proficiency who are taught by using cooperative learning with Team Assisted Individualization (TAI) and conventional learning. Students need to possess self-proficiency ability well so that they could have confidence that they are capable of confronting and of solving their daily life problems in general or mathematical tasks in particular. The population in this research was students of Statistics study program at one of public universities in Makassar. The sampling technique used in this research was purposive sampling, while the instrument used was self-proficiency scale (SPr) which has been validated. The data were analyzed by using parametric and non-parametric statistics. The result of this research is that the achievement of the students' self-proficiency who are taught by using cooperative learning with TAl is better than students who are taught by using conventional learning.
\end{abstract}

Keywords: cooperative learning with TAI, conventional learning, self-proficiency

Received: August 26, 2017; Accepted: September 26, 2017; Published online: October 31, 2017

*Corresponding author: ina_matematika@yahoo.co.id

Citation: Tinungki, G. M. (2017). The role of cooperative with team assisted individualization to improve the students' self proficiency. Journal of Science and Science Education, 1(2), 63-73.

\section{Introduction}

\subsection{Background}

Students should be good cognitive skills, and also have skills related to affective domains, such as the ability of self proficiency (Zimmerman, 1990). Some experts define self proficiency as a person's self-skill, that is the abilities and skills that a person possesses in understanding, executing procedures, and doing something strategically (Kilpatrick et al., 2007).

In studying the students' self-proficiency, the learning model which is predicted to be able to facilitate this study is cooperative learning model with Team Assisted Individualization (TAI). This learning model puts students in small groups consisting of two or more heterogeneous students to help each other in learning the material. The model emphasizes the mutual positive dependence among students, the responsibility of the individual, the face-to-face meeting, the intensive communication, and the group evaluation process such that the classroom management becomes more effective (Johnson \& Johnson, 1998).

Cooperative learning models in addition to helping learners understand difficult concepts, are also useful for helping learners develop cooperative skills, critical thinking, and the ability to help friends. One type of cooperative learning model is cooperative learning model with Team Assisted 
Tinungki: The role of cooperative with team assisted individualization to improve the students' self proficiency

Individualization (TAI). Cooperative learning with TAI is learning where students are put into small groups. Cooperative learning with TAI requires students to participate actively in learning. In addition, students are taught to accept differences within their group. One effort to overcome the problems in this research is to apply cooperative learning model with TAI (Heckler, 2004).

Cooperative learning with TAl is learning aimed at students to solve the problems given by the lecturers in small groups. This type of learning requires students to participate actively in the classroom. On the other hand, students are also taught to accept the differences that may appear in the group. One effort to overcome these problems is a cooperative learning model with TAl. The purpose of this research is to develop self proficiency of students by using cooperative learning model with TAI (Ghaith, 2001).

\section{Material and Method}

\subsection{Self-proficiency}

Student has to possess ability associated with the affective domain, such as self-proficiency. Some experts define self-proficiency as a person's skill in affecting action, effort, persistence, flexibility and realization that is associated with a person's ability (Khairani, 2011). It is closely related to decision making or conclusion drawing which is done without feeling hesitant. Students need to possess self-proficiency ability well so that they could have confidence that they are capable of confronting and of solving their daily life problems in general or mathematical tasks in particular (Neiil, 2005).

The components of Self proficiency (Kilpatrick et al., 2001) consists of (1) conceptual understanding; (2) procedural fluency; (3) strategic competence; (4) adaptive reasoning; and (5) productive disposition. These five self-esteem must be coherent, these strands of self proficiency are not separate, but intertwine into one that represents different aspects of something complex. These competences should be mutually coherent. These strands of personal skills are not something separated, but they are mutually intertwined into one skill that represents different aspects of a complex entity. This skill is not a "congenital" competence from student, but is a combination of knowledge, skills, abilities, and beliefs that gained by the students with the help of educators, curriculum, and learning environment (classroom) that can be relied on (Tinungki, 2015).

\subsection{Cooperative learning with TAI}

Cooperative learning model is a model of learning which emphasizes the use of students groups. The principle that should be upheld related to the cooperative groups is that every student is in a group should have the heterogeneous level of ability (high, intermediate, and low) and if necessary, they must come from different races, cultures, and ethnic groups as well as considering the gender equality (Jacobs, 1988).

The cooperative learning type TAl has learning steps which foster the aspects of mathematics communication ability. The following steps are the steps of the cooperative learning with TAI model:

\section{Step 1: Placement Test}

In this step, the lecturer gives a pretest to the students. This method could also be replaced by observing the test result of the previous material or the average score that the students earned 
during certain duration of study. This step enables lecturer to figure out the students' weakness in particular topics.

Step 2: Teams

This is recognized as an important step in the cooperative learning of TAI. In this step, the lecturer groups the students into some heterogeneous groups consisting of 4-5 students each.

Step 3: Teaching Group

The lecturer explains the material briefly before the tasks given.

Step 4: Student Creative

The lecturer needs to emphasize and to create the students' perception that the individual success is determined by the success of their group.

Step 5: Team Study

The students learn by using the students' worksheet. The lecturer also gives assistant to the students who need help individually. This step could also use the students who have good academic record to help the other members of the group as the peer tutor.

Step 6: Fact test

The lecturer gives small test based on the facts got by the students, for instance, by delivering a quiz.

Step 7: Team Score dan Team Recognition

The next step is that the lecturer gives score to the group's work and gives "salutation" reward towards the group which can pass the tasks well and also towards the group which still fails the tasks, for instance, by recognizing them as "the BEST group" or "the OUTSTANDING group", etc.

Step 8: Whole-Class Units

The final step is that the lecturer re-presents the material in the end of the chapter by using problem solving strategy for all the students in the classroom.

Each component of cooperative learning with TAI model brings benefit to the lecturer, students, top groups and bottom groups who work together completing the academic tasks, namely: the clever students take the responsibility to help the weak group. Thus, they can develop their abilities and skills. The weak students will be assisted in understanding the subject matter, since there is no competition among the students because they work together to solve problems in dealing with different ways of thinking. Students do not only expect assistance from the lecturer, but also motivated to learn fast and accurately in all material. The lecturer could use only half of his/her teaching time so it will be easier to give individual assistance to the students.

\subsection{Method}

This research uses the Quasi-Experimental design. Quasi-Experimental is an experiment that has a treatment, impact measurement, experimental unit but does not use random assignments to create comparisons in order to infer treatment-induced changes (Cook \& Campbell, 1979). Basically Quasi-Experimental research is similar to pure experimental research. This study aims to reveal the causal relationship by involving the control group in addition to the experimental group, but the separation of both groups is not by random technique.

Research samples were taken not randomly to be used as experimental class groups and control class groups. Students who serve as sample of research, before being given treatment, given pre test. Furthermore, the experimental class was given treatment in the form of cooperative learning 
Tinungki: The role of cooperative with team assisted individualization to improve the students' self proficiency

with TAI and control class was given normal learning. Students who become the next sample of research are given post test.

\section{Results and Discussion}

\subsection{Quantitative data analysis of self-proficiency (SPr) data}

In analyzing the SPr data, it began by determining descriptive statistics, which include the mean and standard deviation of initial data, final data based on learning, mathematical prior knowledge (MPK), and overall. The data of descriptive statistics is presented at the following Table 1:

Table 1. Descriptive statistics of SPr data.

\begin{tabular}{|c|c|c|c|c|c|c|c|c|c|c|}
\hline \multirow{2}{*}{ MPK } & \multirow{2}{*}{ Stat. } & \multicolumn{3}{|c|}{ Cooperative learning } & \multicolumn{3}{|c|}{ Conventional learning } & \multicolumn{3}{|c|}{ Total } \\
\hline & & Initial & Final & $n$ & Initial & Final & $n$ & Initial & Final & $n$ \\
\hline \multirow{2}{*}{ High } & $\bar{x}_{\mathrm{X}}$ & 120.2 & 151.1 & \multirow{2}{*}{9} & 120.1 & 123.1 & \multirow[b]{2}{*}{13} & 120.7 & 135.1 & \multirow[b]{2}{*}{22} \\
\hline & SSd & 10.3 & 8.9 & & 7.9 & 7.2 & & 9.1 & 9.0 & \\
\hline \multirow{2}{*}{ Intermediate } & $\bar{x}_{\mathrm{X}}$ & 101.5 & 133.8 & \multirow{2}{*}{33} & 101.2 & 119.1 & \multirow[b]{2}{*}{27} & 100.2 & 126.2 & \multirow[b]{2}{*}{60} \\
\hline & SSd & 11.8 & 7.9 & & 7.1 & 8.1 & & 10.2 & 8.8 & \\
\hline \multirow{2}{*}{ Low } & $\bar{x}_{\mathrm{X}}$ & 89.1 & 122.3 & \multirow{2}{*}{8} & 91.1 & 107.2 & \multirow[b]{2}{*}{10} & 89.3 & 109.9 & \multirow[b]{2}{*}{18} \\
\hline & SSd & 8.1 & 6.7 & & 4.9 & 9.1 & & 7.1 & 8.2 & \\
\hline \multirow{2}{*}{ Sum } & $\bar{x}_{\mathrm{X}}$ & 99.8 & 129.9 & \multirow{2}{*}{50} & 105.2 & 120.1 & \multirow{2}{*}{50} & 99.7 & 120.9 & \multirow{2}{*}{100} \\
\hline & SSd & 10.3 & 7.9 & & 7.1 & 6.9 & & 10.9 & 10.1 & \\
\hline
\end{tabular}

Note: Maximum ideal score $=178$

Based on Table 1, it is seen that the average achievement of SPR students who received cooperative learning with TAl was higher than students who received conventional learning, for all levels of previous mathematical knowledge (high, medium and low), also seen the average achievement of SPR students using cooperative learning with TAl were higher than $r$ students using conventional learning.

The average difference test in knowing there is difference mean achievement of SPr students who use cooperative learning with TAI and students by using conventional learning. Needs analysis is done first, including normality test and homogeneity variance test. Kolmogorov-Smirnov (K-S) test was performed to test the Normality of SPR achievement data with SPSS 22.0 software. The results can be seen in Table 2 .

Table 2. Test of normality of SPr achievement data.

\begin{tabular}{cccccc}
\hline No & Group & $\boldsymbol{n}$ & Value of $\boldsymbol{K}-\boldsymbol{S}$ & Sig. & $\boldsymbol{H}_{\boldsymbol{0}}$ \\
\hline 1 & Experiment & 50 & 0.082 & 0.191 & Accepted \\
2 & Control & 50 & 0.071 & 0.099 & Accepted \\
\hline
\end{tabular}

Ho: data is normally distributed

\subsection{Analysis of SPr achievement data}

MPK levels (high, medium and low) are seen from Table 1, which shows that, overall, the average achievement of students' SPr by using cooperative learning with TAl is higher than that of students using conventional learning. Figure 1 shows the percentage of SPr achievement for both groups. 


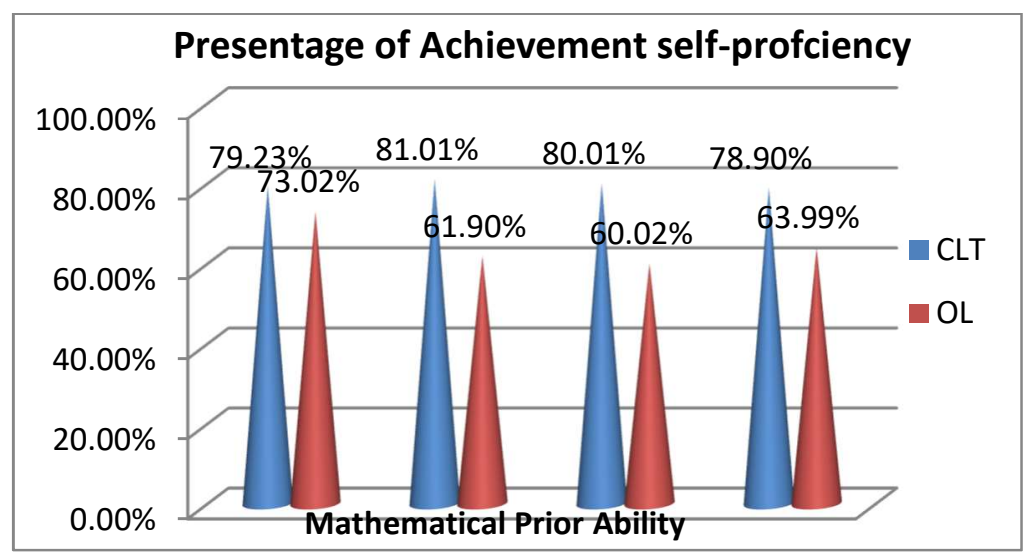

Figure 1 Percentage of students' SPr achievement based on class learning group, initial mathematical ability, and overall.

Figure 1 shows that the percentage of overall for the SPr achievement of student taught by using cooperative learning with TAl is higher than students taught by using conventional learning. The percentage of the SPr achievement for both classes is at intermediate level. If we see based on MPK level, the percentage of SPr achievement in each MPK level for students taught by using cooperative learning with TAI is also higher than the students taught by using conventional learning. For the students with high MPK level, the SPr achievement percentage is also at high level of MPK for both using cooperative and conventional learning, while for intermediate and low MPK level, the SPr percentage is at intermediate MPK level.

\subsection{Comparison of SPr achievement based on learning for overall}

Test of two means difference was done to find out if there is difference between mean of SPr achievement of the student taught by using cooperative learning and students taught by using conventional learning for overall. Before performing this test, we performed analysis of the requirements, namely the test of normality and test of variance homogeneity. Test of KolmogorovSmirnov (K-S) with the help of SPSS 22.0 program resulted in Table 2.

Table 2. Test of normality of SPr achievement data.

\begin{tabular}{cccccc}
\hline No & Group & $\boldsymbol{n}$ & Value of $\boldsymbol{K}-\boldsymbol{S}$ & Sig. & $\boldsymbol{H}_{\mathbf{0}}$ \\
\hline 1 & Experiment & 50 & 0.069 & 0.186 & Accepted \\
2 & Control & 50 & 0.061 & 0.099 & Accepted \\
\hline
\end{tabular}

$H_{0}$ : data is normally distributed

The result of analysis based on Table 2 shows that the significance value (Sig) of SPr achievement data for both groups are more than 0.05 . This indicates that the data is normally distributed. The next step is testing its variance homogeneity by using Levene test. The result is presented in Table 3.

Table 3. Test of variance homogeneity of SPr achievement data.

\begin{tabular}{cccccc}
\hline Learning & Statistic Levene $(\boldsymbol{F})$ & $\boldsymbol{d f _ { 1 }}$ & $\boldsymbol{d f _ { 2 }}$ & Sig. & $\boldsymbol{H}_{\boldsymbol{0}}$ \\
\hline $\begin{array}{c}\text { CL with TAl } \\
\text { Conventional }\end{array}$ & 0.199 & 1 & 97 & 0.799 & Accepted \\
\hline
\end{tabular}

$H_{0}$ : Variance of the two data groups is homogenous 
Tinungki: The role of cooperative with team assisted individualization to improve the students' self proficiency

Table 4. Test of mean difference of SPr achievement data.

\begin{tabular}{ccccccc}
\hline Number & Group & $\boldsymbol{n}$ & Mean & $\boldsymbol{t}$ & Sig. (1-tailed) & $\boldsymbol{H}_{\mathbf{0}}$ \\
\hline 1 & Experiment & 50 & 146.1 & \multirow{2}{*}{3.012} & \multirow{2}{*}{0.005} & \multirow{2}{*}{ Rejected } \\
2 & Control & 50 & 130.9 & & & \\
\hline
\end{tabular}

The result of analysis based on Table 3 shows that the significance value (Sig) of Levene test for SPr achievement data is more than 0.05 . This indicates that the data have a homogenous variance. The next step is $t$ testing to find out whether there is mean difference on both groups of overall SPr achievement data by using SPSS 22.0 program. The result is shown in Table 4.

We can see in Table 4 that the significance value (Sig) of the mean difference test is less than 0.05 , then the null hypothesis is rejected. Thus, the mean of SPr achievement of the students taught by using cooperative learning is better than the students taught by using conventional learning.

\subsection{Comparison of SPr achievement based on learning and MPK}

In order to observe whether there is a mean difference of the two SPr achievement data groups after being taught by using cooperative learning and conventional learning in accordance with the level of MPK, then we have to perform mean difference test. Before performing this test, we performed analysis of the requirements, namely the test of normality and test of variance homogeneity. Test of Kolmogorov-Smirnov (K-S) with the help of SPSS 22.0 program resulted in Table 5.

Table 5. Test of normality of SPr achievement data based on MPK level.

\begin{tabular}{cccccc}
\hline MPK & Learning & $\boldsymbol{N}$ & Nilai $\boldsymbol{K}-\boldsymbol{S}$ & Sig. & $\boldsymbol{H}_{\boldsymbol{0}}$ \\
\hline \multirow{2}{*}{ High } & Cooperative & 9 & 0.231 & 0.190 & Accepted \\
& Conventional & 13 & 0.190 & 0.200 & Accepted \\
\multirow{3}{*}{ Intermediate } & Cooperative & 33 & 0.140 & 0.049 & Accepted \\
& Conventional & 27 & 0.088 & 0.190 & Accepted \\
& Cooperative & 8 & 0.216 & 0.097 & Accepted \\
& Conventional & 10 & 0.189 & 0.190 & Accepted \\
\hline
\end{tabular}

$H_{0}$ : Data is normally distributed

Table 6. Test of variance homogeneity of SPr achievement data.

\begin{tabular}{cccccc}
\hline MPK & Statistic Levene $(\boldsymbol{F})$ & $\boldsymbol{d} \boldsymbol{f}_{\mathbf{1}}$ & $\boldsymbol{d} \boldsymbol{f}_{\mathbf{2}}$ & Sig. & $\boldsymbol{H}_{\mathbf{0}}$ \\
High & 0.99 & 1 & 12 & 0.810 & Accepted \\
Intermediate & 11.88 & 1 & 68 & 0.090 & Accepted \\
Low & 1.099 & 1 & 11 & 0.299 & Accepted \\
\hline
\end{tabular}

$H_{0}$ : Variance of the two data groups is homogenous

Table 7. Test of mean difference SPr achievement data based on MPK level.

\begin{tabular}{|c|c|c|c|c|c|}
\hline MPK & Learning & Mean & $t$ & $\begin{array}{c}\text { Sig. } \\
\text { (1-tailed) }\end{array}$ & $H_{0}$ \\
\hline High & $\begin{array}{l}\text { Cooperative } \\
\text { Conventional }\end{array}$ & $\begin{array}{l}156.3 \\
126.2\end{array}$ & 4.090 & 0.020 & Rejected \\
\hline Intermediate & $\begin{array}{l}\text { Cooperative } \\
\text { Conventional }\end{array}$ & $\begin{array}{l}146.2 \\
116.9\end{array}$ & 4.299 & 0.001 & Rejected \\
\hline Low & $\begin{array}{l}\text { Cooperative } \\
\text { Conventional }\end{array}$ & $\begin{array}{l}115.2 \\
109.2\end{array}$ & 3.807 & 0.000 & Rejected \\
\hline
\end{tabular}


The result of analysis based on Table 5 shows that the significance value (Sig) of SPr achievement data for all level of MPK are more than 0.05. This indicates that the data is normally distributed. The next step is testing its variance homogeneity by using Levene test. The result is presented in Table 6.

The result of analysis based on Table 6 shows that the significance value (Sig) of Lavene test for SPr achievement data is more than 0.05 . This indicates that the data have a homogenous variance. The next step is t testing to find out whether there is mean difference on both groups of SPr achievement data based on their MPK level by using SPSS 22.0 program. The result is shown in Table 7.

We can see in Table 7 that the significance value (Sig) of the mean difference test for SPr achievement at all MPK level are less than 0.05 , then the null hypothesis is rejected. Thus, the mean of SPr achievement of the students taught by using cooperative learning is better than the students taught by using conventional learning.

The next step is to conduct a one-way ANOVA test to analyze whether there is a mean difference of student achievement data taught by using cooperative learning based on MPK level. Before doing this, of course, test of normality and homogeneity are performed. The result shown in Table 5 has already given that the data is normally distributed. The next step is performing homogeneity test using the statistical Levene test, and the results presented in Table 8 below.

The result of analysis based on Table 8 shows that the significance value (Sig) of Lavene test for SPr achievement data is more than 0.05 . This indicates that the data have a homogenous variance.

The next step is to conduct a one-way ANOVA test with the help of the SPSS 22.0 program in order to observe whether there is a mean difference of SPr achievement data of the student using cooperative learning based on MPK level. The results are presented in Table 9.

Table 8. Test of variance homogeneity SPr achievement data based on MPK level using cooperative learning with TAI.

\begin{tabular}{ccccc}
\hline Statistic Levene $(\boldsymbol{F})$ & $\boldsymbol{d f _ { 1 }}$ & $\boldsymbol{d f _ { 2 }}$ & Sig. & $\boldsymbol{H}_{0}$ \\
\hline 15.073 & 2 & 48 & 0.509 & Ho $_{0}$ accepted \\
\hline
\end{tabular}

$H_{0}$ : Variance among groups data is homogenous

Table 9. Test of one-way ANOVA SPr achievement data based on MPK level using cooperative learning with TAI.

\begin{tabular}{lccccc}
\hline & Sum of Square & $\boldsymbol{d f}$ & Mean of Sum of Square & $\boldsymbol{F}$ & Sig. \\
\hline $\begin{array}{l}\text { Among } \\
\text { Groups }\end{array}$ & 20228.181 & 2 & 10193.091 & 47.301 & 0.000 \\
$\begin{array}{l}\text { Within } \\
\text { Groups }\end{array}$ & 10228.792 & 48 & 219.078 & & \\
Total & 31743.009 & 50 & & & \\
\hline
\end{tabular}

$\mathrm{H}_{0}$ : There is no mean difference of the groups

The analysis of the Post Hoc Test used Scheffe test by using SPSS 22.0 program. The result presented in Table 10. The results of the analysis based on Table 10 above indicate that, based on the significance value (sig) of the Scheffe test towards the pair of MPK groups of high and intermediate, the pair of MPK groups of high and low, and the pair of MPK groups of intermediate and low, are 
Tinungki: The role of cooperative with team assisted individualization to improve the students' self proficiency

less than 0.05. Thus, it indicates that there is a significant difference of mean of SPr achievement between the pair of MPK groups of high and intermediate, the pair of MPK groups of high and low, and the pair of MPK groups of intermediate and low. Finally, after seeing the results of mean value, mean difference, and Scheffe testing, we can conclude that the SPr achievement of students taught by using cooperative learning with high level of MPK is different with the intermediate and low level of MPK. This value is also different between intermediate level of MPK with low level of MPK.

Table 10. Scheffe test for SPr achievement data between pair of MPK group by using cooperative learning with TAI.

\begin{tabular}{ccccccc}
\hline MPK $(\boldsymbol{I})$ & MPK $(\boldsymbol{J})$ & Mean $(\boldsymbol{I})$ & Mean $(\boldsymbol{J})$ & $\begin{array}{c}\text { Mean } \\
\text { Difference }\end{array}$ & Sig. & $\boldsymbol{H}_{\mathbf{0}}$ \\
\hline High & Intermediate & 38.902 & 25.3 & $5.941^{*}$ & 0.000 & Rejected \\
High & Low & 69.772 & 24.5 & $8.010^{*}$ & 0.000 & Rejected \\
Intermediate & Low & 36.776 & 21.2 & $7.801^{*}$ & 0.000 & Rejected \\
\hline
\end{tabular}

$\mathrm{H}_{0}$ : There is no mean difference between two groups of data ${ }^{*}$ : significant

Table 11. Test of variance homogeneity SPr achievement data based on learning and MPK.

\begin{tabular}{ccccc}
\hline Statistic Levene $(\boldsymbol{F})$ & $\boldsymbol{d} \boldsymbol{f}_{1}$ & $\boldsymbol{d f _ { 2 }}$ & Sig. & $\boldsymbol{H}_{0}$ \\
\hline 2.388 & 2 & 98 & 0.091 & $\mathrm{H}_{0}$ diterima \\
\hline
\end{tabular}

$H_{0}$ : Variance among data groups is homogenous

The next step is analyzing whether there is interaction between the cooperative learning and conventional learning as well as the level of MPK (high, intermediate, and low) towards the achievement of the SPr. Thus, two-way ANOVA test is conducted. Before doing two-way ANOVA test, we have to do the requirements testing, namely the test of normality and homogeneity. The result of test of normality is shown in Table 5 , showing that the data is normally distributed. While the statistical tests for its homogeneity is conducted by using SPSS 22.0 program as shown in Table 11.

Based on the results shown in Table 11, the value of statistical significance Lavene test is more than 0.05 . This indicates that the data has a homogeneous variance. The next step is to observe whether there are interactions between the cooperative learning and conventional learning towards the achievement of the SPr. Thus, a two-way ANOVA test was used. With the help of the SPSS 22.0 program, we can see result shown in Table 12.

The results of the analysis based on Table 12 , the value of significance (sig) learning less than 0.05 , this indicates that there is a significant difference towards the achievement of the SPr with MPK level. The next step is observation of the interaction between learning and the level of MPK against achievement. The results show the value of their significance less than 0.05 . This indicates that there is an interaction between the learning and achievement of the SPr against MPK level. The result of the existence of such interactions can be shown above, based on the difference of student achievement of the SPr by using cooperative learning with TAI and conventional learning.

The mean difference of students' SPr achievement taught by using cooperative learning with TAI and conventional learning at high level of MPK and intermediate level of MPK are similar. However, the mean of SPr achievement of the student cooperative learning with TAl and students with conventional learning at low level of MPK is smaller than the high level and intermediate level of MPK. 
Table 12. Test of two-way ANOVA SPr achievement data based on learning and MPK.

\begin{tabular}{clclcc}
\hline Source & $\begin{array}{l}\text { Type III Sum of } \\
\text { Squares }\end{array}$ & $\boldsymbol{d f}$ & Mean Square & F & Sig. \\
\hline Corrected Model & $18197.677^{\mathrm{a}}$ & 5 & 4123.221 & 19.919 & 0.000 \\
Intercept & 877729.001 & 1 & 889788.001 & 4729.186 & 0.000 \\
Learning & 7568.122 & 2 & 3789.568 & 19.711 & 0.000 \\
MPK & 711.481 & 1 & 712.387 & 4.077 & 0.019 \\
Learning and MPK & 7107.599 & 2 & 3454.782 & 19.002 & 0.000 \\
Error & 15665.601 & 94 & 183.867 & & \\
Total & 1620137.001 & 100 & & & \\
Corrected Total & 34866.269 & 99 & & &
\end{tabular}

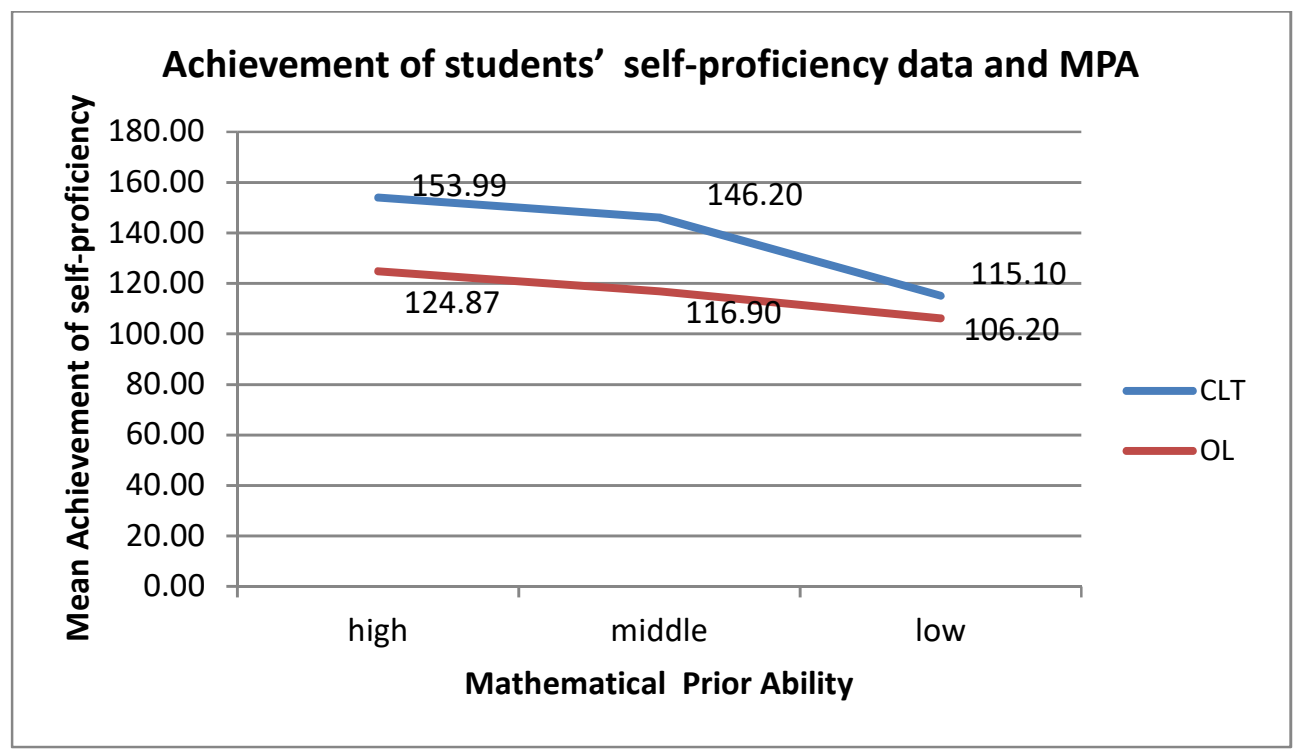

Figure 2. Interaction between learning and MPK towards SPr achievement.

Figure 2 shows that the mean of students' achievement of SPr at all levels of MPK (high, intermediate, and low) who are taught by using cooperative learning with TAl is higher than the students taught by using conventional learning.

\subsection{Qualitative data of learning}

Based on the results of observation and interview towards some students, they admit that the achievement of self-proficiency is one of components and critical factors of self-regulated learning. Thus, students need to possess a good self-proficiency such that the students could have confidence that they could confront and solve life problems in general, and mathematics tasks in particular.

\section{Example 1:}

If $\mathrm{X}$ is a random variable with a function of solid probability:

$$
f(x)= \begin{cases}\frac{x^{2}}{3} & ,-1<x<2 \\ 0 & , \text { otherwise }\end{cases}
$$

then search for the variance of the random variable $g(x)=4 x+3$ 
Answer:

$$
\begin{aligned}
\sigma_{4 X+3}^{2} & =E\left\{\left[(4 X+3)-\mu_{4 X+3}\right]^{2}\right\}=E\left\{[4 X+3-8]^{2}\right\} \\
& =E\left[(4 X-5)^{2}\right]=\int_{-1}^{2}(4 x-5)^{2}\left(\frac{x^{2}}{3}\right) d x \\
& =\frac{1}{3} \int_{-1}^{3}\left(16 x^{4}-40 x^{3}+25 x^{2}\right) d x \\
& =\frac{1}{3}\left(\frac{16}{5} x^{5}-\frac{40}{4} x^{4}+25 x^{3}\right) \mid=\frac{51}{5}
\end{aligned}
$$

So the variability of random variables $g(x)=4 x+3$ is $\frac{51}{5}$.

\section{Example 2:}

Let $X_{1}, X_{2}$, and $X_{3}$ are three independent random variables and each has probability density function (PDF) shaped $f(x)=2 x, 0<x<1$, and zero for the other. Joint PDF $X_{1}, X_{2}$, and $X_{3}$ is given by

$$
F\left(x_{1}, x_{2}, x_{3}\right)=\left\{\begin{array}{cl}
8 x_{1} x_{2} x_{3} & , 0<x_{1}, x_{-} 2, x_{3}<1 \\
0 & , \text { otherwise }
\end{array}\right.
$$

Expected value for $u\left(X_{1}, X_{2}, X_{3}\right)=5 X_{1} X_{2}^{2}+3 X_{2} X_{3}^{4}$ is

$$
E\left[5 X_{1} X_{2}^{2}+3 X_{2} X_{3}^{4}\right]=\int_{0}^{1} \int_{0}^{1} \int_{0}^{1}\left(5 x_{1} x_{2}^{2}+3 x_{2} x_{3}^{4}\right) 8 x_{1} x_{2} x_{3} d x_{3} d x_{2} d x_{1}=2 .
$$

Let $Y$ is the maximum of the three random variables, be searched $P\left(Y<\frac{1}{2}\right)$. Since $Y$ is the maximum of the three random variables, then

$$
P\left(Y<\frac{1}{2}\right)=P\left(X_{1}<\frac{1}{2}, X_{2}<\frac{1}{2}, X_{3}<\frac{1}{2}\right)=\int_{0}^{\frac{1}{2}} \int_{0}^{\frac{1}{2}} \int_{0}^{\frac{1}{2}} 8 x_{1} x_{2} x_{3} d x_{3} d x_{2} d x_{1}=\frac{1}{64} .
$$

The distribution function of $Y$ is

$$
G(y)=P(Y \leq y)=\left\{\begin{array}{cl}
0 & , y<0 \\
y^{6} & , 0 \leq y<1 \\
1 & , y \geq 1
\end{array}\right.
$$

PDF for $Y$ is $g(y)=G^{\prime}(y)=6 y^{5}, 0<y<1$, and zero for the other.

Based on the answers above, shows that the average student can answer well because they have a good self-proficiency as well, after gaining cooperative learning with TAl. While the students are taught using conventional learning, there is no significant improvement in their self-proficiency ability. Thus, the achievement of students' learning skills that cooperative learning is better than students who receive conventional learning.

\section{Conclusion and Recommendation}

Based on the results of comparative analysis of student self-proficiency achievement can be drawn the conclusion as follows.

(1) Based on the mean and test results of mean student achievement self-proficiency differences, Student Self-proficiency achievement taught by using cooperative learning with TAl is better than students being taught using conventional learning for the whole and for each mathematical level. prior knowledge (MPK). Thus, we can say that by using cooperative learning with TAl the achievement of self-proficiency is better than conventional learning.

(2) There is an interaction between cooperative learning with TAl and conventional learning as well as MPK (high, medium, and low) level on student's own learning achievement.

Expected for further research, it is hoped that the role of self-proficiency can be more studied in the affective scale (affective domain) and mathematical ability (cognitive domain). 


\section{References}

Ghaith, G. M. (2001). Learners' perceptions of their STAD cooperative experiences. System, 29(2), $289-301$.

Heckler, A. F. (2004). Measuring Student Learning by Pre and Post testing: absolute Gain normalized Gain. American Journal of Physics.

Jacobs, G. (1988). Cooperative goal structure: A way to improve group activities. ELT Journal, 42(2), 97-101.

Johnson, D, W., \& Johnson, R. T. (1998). Cooperative learning and social interdependence theory. In R. Scott Tindale et al. (Eds.), Theory and Research on Small Groups (pp. 9-35). New York: Plenum Press.

Kilpatrick, J., Swafford, J., \& Findell, B. (Eds.). 2001. Adding it up: helping children learn mathematics. Washington, DC: National Academy Press.

Khairani, 2011. The development and construct validation of the mathematics proficiency test for 14-yearsold students. Asia Pasific Journal of Educator and Education, 26(1), 33-50.

Tinungki, G. M., 2015. The role of cooperative learning type team assisted individualization to improve the students' mathematics communication ability in the subject of probability theory. Journal of Education and Practice, 6(32), 2015. 